\title{
Plasmacytoid Myoepithelioma of the Palate: Case Report
}

\author{
Matina T. Zormpa $\cdot$ Asimina S. Sarigelou \\ Anna N. Eleftheriou • Anthoula S. Assimaki • \\ Alexandros E. Kolokotronis
}

Received: 14 July 2010/Accepted: 22 November 2010/Published online: 5 December 2010

(C) Springer Science+Business Media, LLC 2010

\begin{abstract}
Myoepitheliomas are extremely rare benign neoplasms of salivary glands. They represent $1-1.5 \%$ of all salivary gland tumors. They occur, principally, in the parotid gland and infrequently in minor salivary glands. There are distinct histological and immunohistochemical characteristics of the tumor which aid in the diagnosis. Myoepithelioma of the palate is uncommon and only a limited number of cases has been reported in the English literature. Herein, a case of plasmacytoid type of myoepithelioma of the palate in an adult female is presented along with review of the literature.
\end{abstract}

Keywords Myoepithelioma - Plasmacytoid - Salivary gland neoplasms $\cdot$ Palate tumor

M. T. Zormpa · A. S. Sarigelou - A. N. Eleftheriou ·

A. S. Assimaki - A. E. Kolokotronis

Department of Oral Medicine and Maxillofacial Pathology,

School of Dentistry, Aristotle University of Thessaloniki,

Thessaloniki, Greece

M. T. Zormpa ( $\square)$

3 Komninon St, 50100 Kozani, Greece

e-mail: zormpam@gmail.com

A. S. Sarigelou

9A Zahou St, Kato Toumpa, 54454 Thessaloniki, Greece

A. N. Eleftheriou

17 Mitropolitou Efstathiou St, KatoToumpa,

54454 Thessaloniki, Greece

\section{A. S. Assimaki}

64 Mitropoleos St, 54622 Thessaloniki, Greece

A. E. Kolokotronis

73 Ermou St, 54623 Thessaloniki, Greece

\section{Introduction}

The term 'myoepithelioma' was first introduced by Sheldon in 1943 [1]. Myoepithelioma (ME) is defined as a benign, solid tumor composed predominantly or entirely of neoplastic cells of myoepithelial differentiation [2]. Normally, myoepithelial cells are essential component of some exocrine glands such as salivary glands, lacrimal glands, sweat glands and mammary glands [3]. MEs represent $1-1.5 \%$ of all salivary gland neoplasms $[3,4]$. Their most frequent location is parotid glands ( $40 \%$ of all cases). Less common locations include the submandibular gland or the minor salivary glands that are distributed throughout the oral cavity. MEs of the soft or hard palate account for $21 \%$ of all cases and for $93 \%$ of intraoral cases $[3,5]$. In the international literature the tumor is reported to appear at any age between 8 and 85 years with an average age of 40 years and a peak at the third decade $[4,6]$.

The aim of this paper is to describe a case of plasmacytoid ME of the palate, focusing on the clinical, histological and immunohistochemical features along with a review of the literature. To our knowledge, there have been published only 18 previous such cases in the English literature (Table 1).

\section{Case Report}

A 29-year-old woman presented on April 2009 with an asymptomatic, well-circumscribed, solid mass located close to the midline and close to the border of the hard and soft palate, opposite the upper right first molar tooth (Fig. 1). The lesion was round, $0.5 \mathrm{~cm}$ in diameter and covered by slightly red mucosa. The patient had first noticed the lesion 2 years previously. Since then, there was 
Table 1 Clinical features of plasmacytoid myoepithelioma of the palate

\begin{tabular}{|c|c|c|c|c|}
\hline Case & Age/sex & Location & Treatment & Follow up \\
\hline Kahn and Schoub 1973 [14] & $17 / \mathrm{F}$ & Hard palate & Surgery & $\mathrm{NP}$ \\
\hline Sciubba and Goldstein 1976 [15] & $22 / \mathrm{M}$ & Right palate & Electrosurgery & NR after 2 years \\
\hline Nesland et al. 1981 [16] & $18 / \mathrm{F}$ & Anterior soft palate & Surgery & NR after 1 month \\
\hline Barnes et al. 1985 [17] & $24 / \mathrm{F}$ & Midline hard palate & Surgery & NR after 3 years \\
\hline Lins and Gnepp 1986 [18] & $8 / \mathrm{F}$ & Right soft palate & Surgery & NR after 1 year \\
\hline Ohtake et al. 1997 [19] & $26 / \mathrm{F}$ & Right palate & Surgery & NR after 1 year \\
\hline Kanazawa et al. 1999 [9] & $42 / \mathrm{F}$ & Left hard palate & Surgery & NR after 2 years \\
\hline Taylor and Tighe 1999 [20] & $85 / \mathrm{F}$ & Right soft palate & Enucleation & NR after 1 year \\
\hline Makoto et al. 2003 [21] & $65 / \mathrm{F}$ & Right palate & Surgery & NR after 2 years \\
\hline Bakshi et al. 2007 case 1 [7] & $38 / \mathrm{M}$ & Right soft palate & Surgery & NR after 4 years \\
\hline Bakshi et al. 2007 case 2 [7] & $35 / \mathrm{M}$ & Left hard palate & Surgery & NR after 6 months \\
\hline Bakshi et al. 2007 case 3 [7] & $65 / \mathrm{M}$ & Right hard palate & Surgery & NR after 3 months \\
\hline Zelaya et al. 2007 [4] & $28 / \mathrm{F}$ & Left hard palate & Surgery & NR after 18 months \\
\hline Cruz Perez et al. 2007 [2] & $13 / \mathrm{M}$ & Hard \& soft palate border & Surgery & NR after 6 years \\
\hline Kim et al. 2007 case 1 [22] & $63 / \mathrm{M}$ & Posterior soft palate & Surgery & NP \\
\hline Kim et al. 2007 case 2 [22] & $65 / \mathrm{F}$ & Left soft palate & Surgery & NP \\
\hline Rastogi et al. 2008 [23] & $33 / \mathrm{M}$ & Hard palate & Surgery & NR after 1 year \\
\hline Kim et al. 2009 [24] & $52 / \mathrm{F}$ & Left hard palate & Surgery & NR after 10 years \\
\hline Present case & $29 / F$ & Hard \& soft palate border & Surgery & NR after 17 months \\
\hline
\end{tabular}

$M$ male, $F$ female, $N P$ not provided, $N R$ no reccurence

a gradual increase in size. Intraoral periapical and occlusal upper jaw radiographic examination showed no destruction of the subjacent palatal bone. There was no lymphadenopathy. The medical history of the patient was noncontributory. A total excision of the lesion was carried out under local anesthesia. No evidence of tumor recurrence has been observed on 17-month follow up (date of the present report).

The specimen was fixed in $10 \%$ buffered formaldehyde and embedded in paraffin. Serial sections ( $4 \mu \mathrm{m}$ thickness)

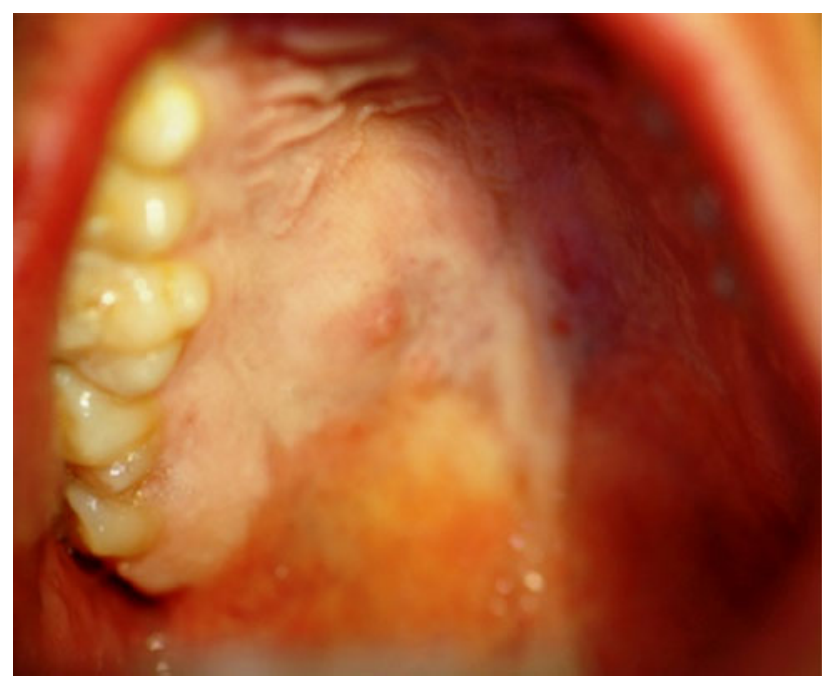

Fig. 1 Clinical appearance of the lesion were taken from the block and stained with hematoxylin$\operatorname{eosin}(\mathrm{H}+\mathrm{E})$.

Grossly, the lesion consisted of fragments of gray-white tissue measuring $0.4 \times 0.7 \mathrm{~cm}$. Microscopic examination revealed cords, clusters and sheets of homogenous, large cells with plasmacytoid characteristics presenting round or ovoid eccentric nuclei and a prominent eosinophilic cytoplasm (Figs. 2, 3). Between these groups of cells abundant myxoid stroma could be discerned. The mass was surrounded by a thin, fibrous capsule outside of which small salivary gland acini were found. Ductal and acinar differentiation was absent. There was no evidence of malignancy such as mitotic figures, necrosis, interstitial hemorrhage or infiltration of the adjacent tissues. The histopathological diagnosis was consistent with benign ME of plasmacytoid type.

Immunohistochemical studies were performed by avidin-biotin peroxidase complex technique. All stains were performed using commercially available antibodies in a Ventana XT instrument (Ventana Systems, Tucson, AZ). The antibody sources and dilutions are listed in Table 2.

Immunohistochemical analysis revealed strong and diffuse positivity of all myoepithelial cells against vimentin, S-100 protein, cytokeratin AE1/AE3 and calponin (Figs. 4, $5,6,7)$. However, a variable immunoreactivity of some myoepithelial cells was detected against cytokeratine 5/6 (50\% of neolpastic cells) while some of the myoepithelial cells showed focal positivity against p63 (40\% of 


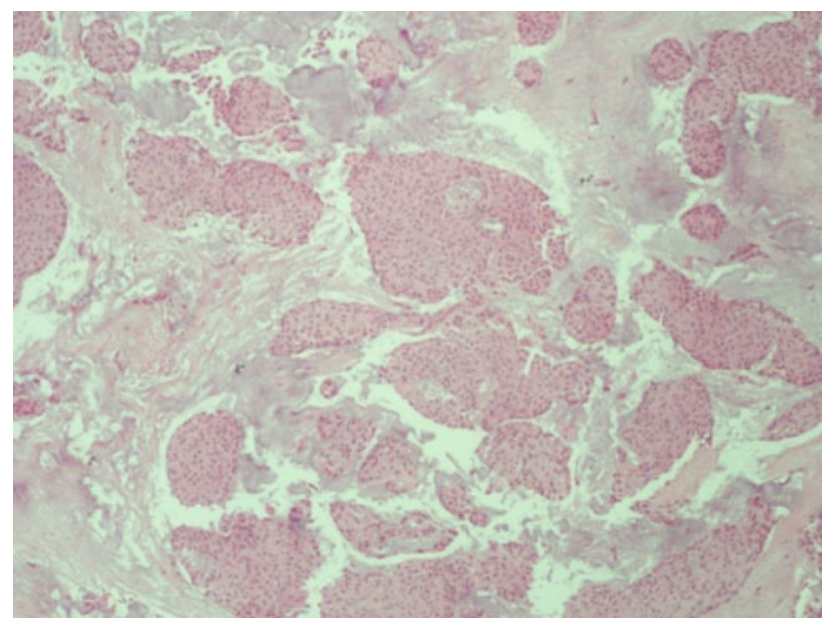

Fig. 2 Sheets of neoplastic cells $(\mathrm{HE} \times 100)$

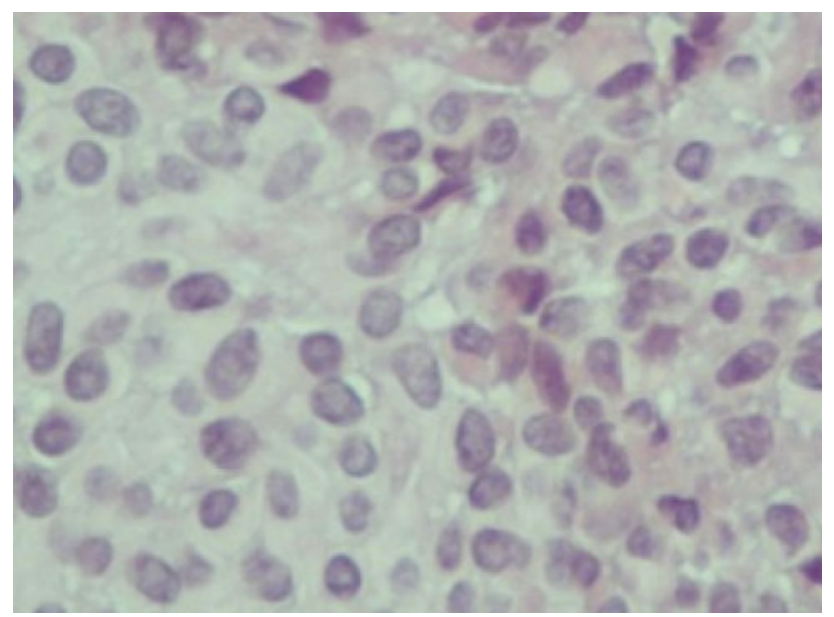

Fig. 3 The plasmacytoid cells (HE400)

Table 2 Immunohistichemical details: antibody sources and dilutions

\begin{tabular}{lll}
\hline Antibody & Source & Dilution \\
\hline CK 5/6 & DAKO & $1: 80$ \\
P63 & DAKO & $1: 100$ \\
Calponin & DAKO & $1: 50$ \\
Vimentin & DAKO & $1: 200$ \\
S100 & DAKO & $1: 400$ \\
\hline
\end{tabular}

neoplastic cells). These findings confirmed the diagnosis of benign ME.

\section{Discussion}

Myoepithelial cells, the essential component of MEs, are contractive cells which are located between the basal lamina and the acinar and ductal cells in exocrine glands

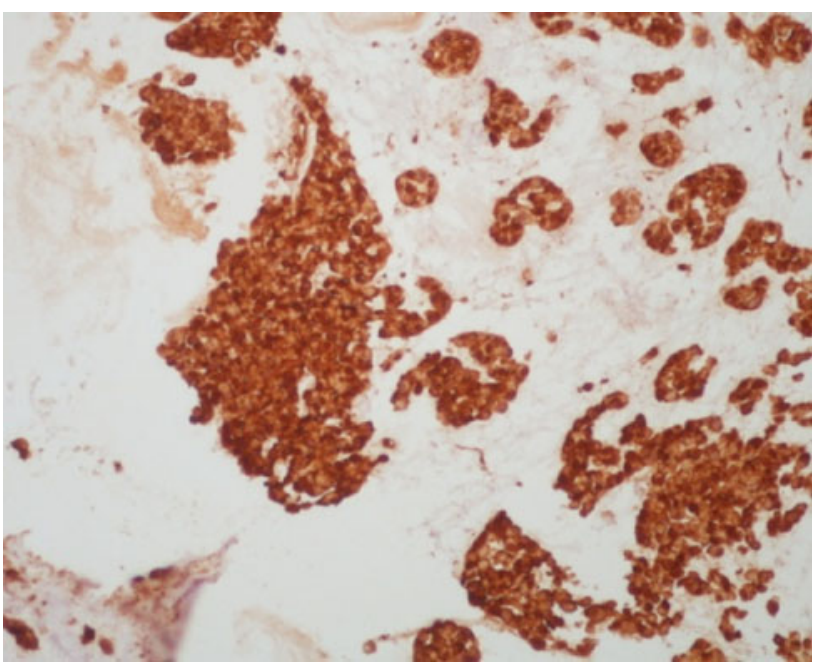

Fig. 4 Positive immunoreactivity against vimentin $(\times 200)$

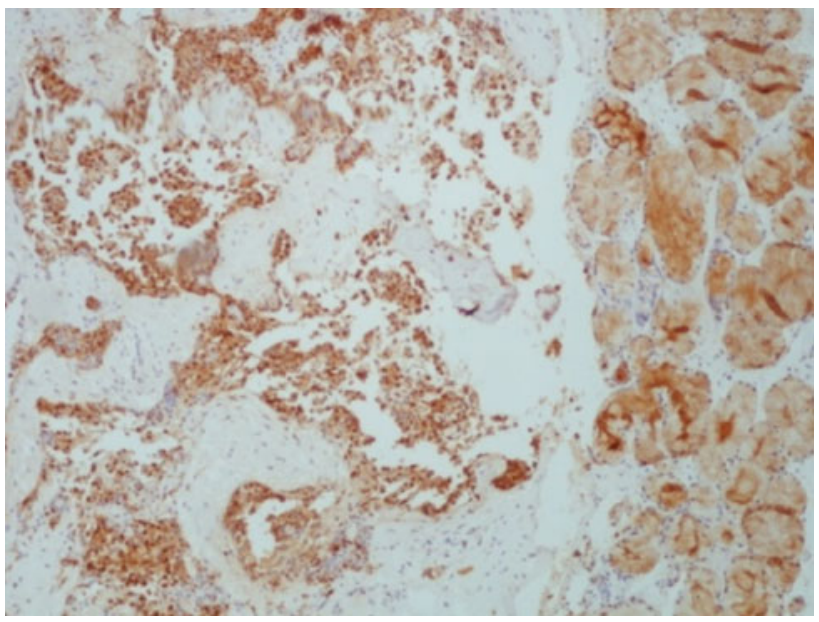

Fig. 5 Positive immunoreactivity against S-100 protein $(\times 100)$

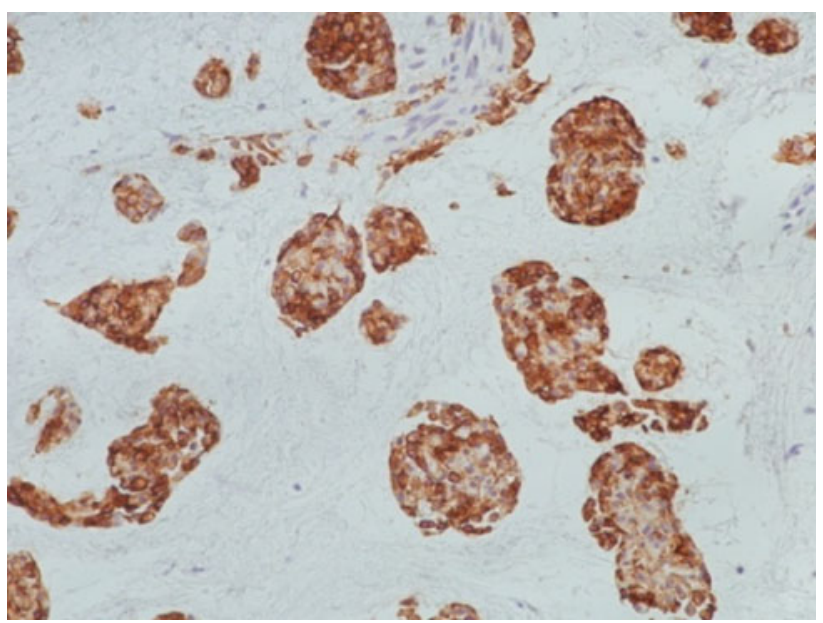

Fig. 6 Positive immunoreactivity against cytokeratin AE1/AE3 $(\times 200)$ 


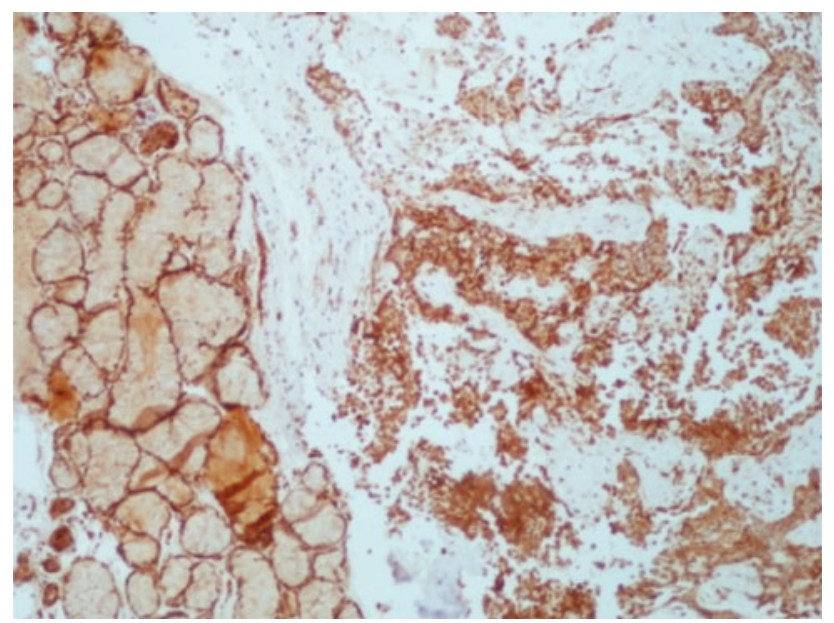

Fig. 7 Positive immunoreactivity against calponin $(\times 100)$

including salivary glands. They are ectodermal in origin but function as mesodermal cells [7]. According to some reports these cells participate in some neoplastic processes such as tumor cell differentiation, invasion, angiogenesis and synthesis of basal membrane [8].

Clinically, ME usually appears as an asymptomatic, slowly growing submucosal mass. According to data in Table 1, the tumor presents in a broad age range from 8 to 85 years with a peak of appearance in the 3rd decade of life. From the reported cases, a female:male ratio of 1.7:1 is seen. Similar findings appear in the present case.

Macroscopically, the tumor is well-circumscribed with a yellow-brown, glistening, smooth surface. There is no bone or adjacent soft tissue involvement $[2,5]$.

Histologically, there are four recognized subtypes of ME: spindle-cell, plasmacytoid (or hyaline), epithelioid and clear-cell type [4, 9]. They may appear as single types or in combination (mixed form) [10]. Plasmacytoid ME of palate, as in the present case, is considered a rare entity [4]. Microscopically, a thin capsule surrounds the tumor. It is composed of sheets, nests or mantles of plasma cell-like, round or ovoid, polyhedral cells with eccentric nucleus and distinctive fibrillar, eosinophilic cytoplasm $[4,7]$. The growth pattern varies and may appear as myxoid, nonmyxoid (solid), reticular, microcystic/pseudocystic or cribriform/pseudograndular [11]. Infrequent histological findings are nuclear fissures and intranuclear inclusions [4]. Mitoses are extremely rare [5]. The histological type of the tumor is related to its location and behavior. Particularly, it seems that spindle-cell and clear-cell type occur more often in parotid glands, while plasmacytoid type occurs more often intraorally, especially in the minor salivary glands of the palate in young patients $[2,5,7]$. Moreover, plasmacytoid type behaves in a benign way while spindle-cell or clear-cell types are present in many malignant cases showing high proliferative activity $[5,8]$.
There are many immunohistochemical studies which demonstrate the variability of myoepithelial neoplastic cells' expression against some certain antibodies. Particularly, S-100 protein, CK(AE1/AE3), CK(5/6), vimentin and calponin are consistently positive markers in the tumor cells. They are very sensitive but non-specific markers. In most tumors, a-SMA (a-Smooth Muscle Actin) positivity has been observed. For GFAP (Glial Fibrillary Acid Protein), tumor cells may exhibit either positive or negative reaction [3, 7, 9]. In normal myoepithelium CK14 and muscle specific actin are the characteristic immunoreactive markers which are not expressed in neoplastic myoepithelium. Adversely, S-100 protein, vimentin and GFAP are absent in non neoplastic cells [11].

Diagnosis of the tumor is based on evaluation of histological features, although immunohistochemical analysis of the cytoplasmic filament expression confirms the myoepithelial origin of the tumor cells and the final diagnosis [2,9]. Recently, there have been reported some cases of MEs with description of CT and MR images of the mass. By CT, the tumor is well-circumscribed and enhances slightly at contrast administration [12]. MR shows a well-demarcated, homogeneous isointensity mass on T1-weighted images and slightly hyperintensity on T2-weighted images. The mass is mildly enhanced following administration of contrast material [13]. However, diagnosis of MEs exclusively by means of radiologic examination is impossible and biopsy is necessary.

Differential diagnosis of ME includes lesions which also have cells of myoepithelial differentiation as a component. Primarily, the tumor must be separated from pleomorphic adenoma. Based on the histological and behavioral similarities of these two tumors, many authors have considered $\mathrm{ME}$ as a subtype or final end of the spectrum of pleomorphic adenomas [7, 9]. However, World Health Organization (WHO) has separated ME from pleomorphic adenoma and has recognized it as an independent entity which shows less than $5 \%$ or no ductal and acinar differentiation as does the latter [4]. Moreover, the differential diagnosis must include malignant MEs. The malignancy is supported by infiltrative growth, metastasis, necrotic areas, cytologic atypia, high mitotic rate and cellular pleomorphism [3]. It has been suggested that a Ki-67 label index of more than $10 \%$ is diagnostic of myoepithelial carcinoma. Thus, it may be useful in the assessment of cell proliferative activity and in the differential diagnosis between benign and malignant myoepitheliomas [3]. Finally, epithelial-myoepithelial carcinoma, polymorphous low-grade adenocarcinoma and adenoid cystic carcinoma, as well as inflammatory conditions and benign mesenchymal soft tissue tumors such as leiomyoma and schwannoma must be excluded $[3,11]$.

As shown in Table 1, the treatment of choice for MEs, is complete surgical excision with margin of nonlesional 
tissue, without recurrence risk even after 10 years of surgery. Radiation therapy is used only in cases where surgical operation is not feasible [2,3]. Exceptionally, there are studies which have found a recurrence rate of $18 \%[4,7]$.

\section{References}

1. Sheldon WH. So-called mixed tumours of the salivary glands. Arch Pathol. 1943;35:1-20.

2. Cruz Perez DE, Lopes MA, Almeida OP, et al. Plasmacytoid myoepithelioma of the palate in a child. Int $\mathbf{J}$ Paediatr Dent. 2007; 17:223-7.

3. Ferri E, Pavon I, Armato E, et al. Myoepithelioma of a minor salivary gland of the cheek: case report. Acta Otorhinolaryngol Ital. 2006;26:43-6.

4. Zelaya FC, Rivera DQ, Vazquez JLT, et al. Plasmacytoid myoepithelioma of the palate. Report of one case and review of the literature. Med Oral Patol Oral Cir Bucal. 2007;12:552-5.

5. Piattelli A, Fioroni M, Rubini C. Myoepithelioma of the gingiva. Report of a case. J Periodontol. 1999;70:683-7.

6. Astarci HM, Celik A, Sungu N. Cystic clear cell myoepithelioma of the parotid gland. A case report. Oral Maxillofac Surg. 2009;13:45-8.

7. Bakshi J, Parida PK, et al. Plasmacytoid myoepithelioma of palate: three rare cases and literature review. J Laryngol Otol. 2007;121:13-7.

8. Dantas da Silveira EJ, Pereira AL, Fontora MC, et al. Myoepithelioma of minor salivary gland- An immunohistochemical analysis of four cases. Braz J Otorhinolaryngol. 2006;72:528-32.

9. Kanazawa H, Furuya T, Watanabe T, et al. Plasmacytoid myoepithelioma of the palate. J Oral Maxillofac Surg. 1999;57:857-60.

10. Hara H, Oyama T, Kimura M, et al. Case of myoepithelioma originating from the palate: collagenogenesis in myoepithelial tumor cells. Diagn Cytopathol. 1996;15:415-20.
11. Savera AT, Zarbo RJ. Defining the role of myoepithelium in salivary gland neoplasia. Adv Anat Pathol. 2004;11:69-83.

12. Wang S, Shi H, Wang L, et al. Myoepithelioma of the parotid gland: CT imaging findings. AJNR Am J Neuroradiol. 2008; 29:1372-5.

13. Hiwatashi A, Matsumoto S, Kamoi I, et al. Imaging features of myoepithelioma arising from the hard palate. A case report. Acta Radiol. 2000;41:417-9.

14. Kahn LB, Schoub L. Myoepithelioma of the palate: histochemical and ultrastructural observations. Arch Pathol. 1973;95:209-11.

15. Sciubba JJ, Goldstein BH. Myoepithelioma: review of the literature and report of a case with ultrastructural configuration. Oral Surg. 1976;42:328-38.

16. Nesland JM, Sorbiho-Simoses M. Plasmacytoid myoepithelioma of the palate. A case report with ultrastructural findings and review of the literature. J Oral Pathol. 1981;10:14-21.

17. Barnes L, Appel BN, Perez H, et al. Myoepithelioma of the head and neck: case report and review. J Surg Oncol. 1985;28:21-4.

18. Lins JE, Gnepp DR. Myoepithelioma of the palate in a child. Int J Pediatr Otorhinolaryngol. 1986;11:5-13.

19. Ohtake I, Mogi K, Iizuka M, et al. A Case of myoepithelioma of the palate. Int J Oral Maxillofac Surg. 1997;26:256.

20. Taylor J, Tighe JV. A minor salivary gland tumour presenting with dysphagia. J Laryngol Otol. 1999;113:569-72.

21. Makoto Y, Chieko T, Masahiro H, et al. A case of plasmacytoid cell type myoepithelioma of the palate. Jpn J Oral Maxillofac Surg. 2003;49:210-3.

22. Kim HS, Lee WM, Choi SM. Myoepitheliomas of the soft palate: helical CT findings in two patients. Korean J Radiol. 2007;8: $552-5$.

23. Rastogi S, Modi M, Dhawan V, et al. Myoepithelioma of palate. A case report and review of literature. JCDR. 2008;6:1095-9.

24. Kim NR, Cho HE, Ha SY. Cytology of plasmacytoid type myoepithelioma- Report of two cases. Korean J Pathol. 2009; 43:489-93. 